Article

\title{
Efficient Hydrothermal Synthesis of SSZ-13 with Variable Grain Size
}

\author{
Yibao Wang ${ }^{1,2}$, Chen Wang ${ }^{3,4,+}\left(\mathbb{D}\right.$, Jun Wang ${ }^{3}$, Jianqiang Wang ${ }^{3}$, Lei Wang ${ }^{1,2}$, Cheng $\mathrm{Xu}^{1,2}$ and \\ Meiqing Shen ${ }^{3, *}$ \\ 1 State Key laboratory of Engine reliability, Weifang 261061, China; wangyib@weichai.com (Y.W.); \\ wanglei@weichai.com (L.W.); xuc@weichai.com (C.X.) \\ 2 Weichai Power Co., Ltd., Weifang 261061, China \\ 3 Key Laboratory for Green Chemical Technology of State Education Ministry, School of Chemical Engineering \\ \& Technology, Tianjin University, Tianjin 300072, China; chenwang87@nuc.edu.cn (C.W.); \\ wangjun@tju.edu.cn (J.W.); jianqiangwang@tju.edu.cn (J.W.) \\ 4 School of Environment and safety Engineering, North University of China, Taiyuan 030051, China \\ * Correspondence: mqshen@tju.edu.cn \\ + Co-first author.
}

Received: 7 March 2020; Accepted: 7 April 2020; Published: 13 April 2020

\begin{abstract}
To meet the industrial needs for SSZ-13, variable sizes of SSZ-13 with different Si/Al ratios were firstly obtained by conventional hydrothermal synthesis using the seed method. Using a set of characterizations, like X-ray fluorescence (XRF), X-ray diffraction (XRD), and scanning electron microscopy (SEM), the physicochemical structure and size distribution could be traced. After the specific Si/Al ratio of SSZ-13 zeolites was optimized, synthesized by changing the amounts of structure-directing agents (SDAs) and $\mathrm{NaOH}$, the obtained SSZ-13 showed a high degree of crystallinity. With the limitation of the $\mathrm{pH}$ values, the variation of the alkalinity and water content was not helpful to generate different grain sizes of SSZ-13 materials. With the help of ground seed, the various grain sizes of SSZ-13s from 0.4 to $4 \mu \mathrm{m}$ had a similar degree of crystallinity and size distribution. Moreover, due to the identical intensity of the Al peak in the NMR results, the different grain sizes of SSZ-13s had the same acidity. Our study revealed that using the seed method was an easy and efficient way to synthesize SSZ-13s with different sizes.
\end{abstract}

Keywords: SSZ-13; hydrothermal synthesis; different grain sizes; seeding method

\section{Introduction}

Academia and industry have been highly concerned in the last decade with silicoaluminate zeolites of SSZ-13 with the chabzite (CHA) structure, showing the same topological structure as SAPO-34. The SSZ-13 material contains 4-, 6-, and 8-membered ring (MR) units to form a three-dimensional pore structure with a large $7.3 \AA$ cage and 3.8 $\AA$ 8-MR windows [1]. Due to the unique pore system, SSZ-13 has excellent low-/high-temperature hydrothermal stability, and the production selectivity can be widely used in the methanol-to-olefin (MTO) process and NOx removal technology $\left(\mathrm{NH}_{3}\right.$-selective catalytic reduction (SCR)) in the diesel industry [2-5].

According to the informed studies on CHA zeolites, the grain size may influence mass transfer restrictions, and this will in turn influence the catalytic behavior. Some products generated in the methanol-to-olefin (MTO) reaction occupy the entire cage and result in poor catalytic activity [3], while this phenomenon does not occur in the $\mathrm{NH}_{3}-\mathrm{SCR}$ reaction, as all reactants have a smaller diameter than that of the pore size of CHA [6]. Besides that, the grain size could lead to different hydrothermal stabilities and lifetimes. Huang et al. [7] found that the small size of SAPO-34 with a low density of surface acidity and the CHA structure was relatively stable after low-temperature hydrothermal aging. 
In the reaction of MTO, the small size of SSZ-13 or SAPO-34 results in a long lifetime as the small size suppresses phenanthrenes' generation and decreases the coke formation rate [5,8]. In addition, it is reasonable to believe that the small size of zeolites on a honeycomb carrier may increase the backpressure, and that would hinder the reaction process. Taking all these facts into account, the controllable synthesis of variable sizes of SSZ-13 according to the actual situation is an efficient way to cope with all the possible operating conditions in the real situation.

Actually, many methods have been developed to prepare different sizes of CHA zeolites. Regarding SAPO-34 materials, Song et al. [9] found that the size of SAPO-34 could be varied from 0.1 to $1.5 \mu \mathrm{m}$ under microwave radiation. Wang et al. [10] used the ammonium-type organosilane surfactant Trimethoxysilyl)propyl]octade-cyldimethylammonium chloride (TPOAC) and the template diethylamine to synthesize elliptical-like SAPO-34 aggregates, consisting of $50 \mathrm{~nm}$ particles. Wang et al. [11] used a two-step hydrothermal process, with a relatively low-temperature hydrothermal crystallization followed by a high-temperature hydrothermal crystallization, to produce 0.16-0.55 $\mu \mathrm{m}$ SAPO-34 crystallites. Yang et al. [12] used a top-down approach, combining post-synthesis milling and recrystallization, to obtain nanoscale $\mathrm{Cu} / \mathrm{SAPO}-34$ particles of 0.05 to $0.35 \mu \mathrm{m}$. For SSZ-13 zeolites, adding organic compounds into the synthetic precursor solution of SSZ-13 is a common method to generate small-sized SSZ-13 particles. Li et al. [13] added the large molecular surfactant hexadecyl trimethyl ammonium bromide (CTAB) into conventional gel, called a one-pot synthesis procedure, to obtain nano-sized SSZ-13 zeolites. Xu et al. [5] used anionic and cationic organic compounds, polyacrylamide (APAM) and polyacrylamide (CPAM), to produce nano-SSZ-13 zeolites successfully. Hereto, even though some contributions have achieved the generation of small-sized CHA zeolites, the following aspects also deserve much attention. The mentioned synthesis methods usually require another process, and some processes or additives are quite complex and have a high cost, which are not suitable for commercial production. Additionally, the size of most synthesized particles is small, and the size distribution is not uniform, indicating that the obtained particles may easily aggregate and may not be appropriate for real applications. In short, it is important to perform further studies on an easy and efficient method to synthesize different sizes of CHA with a uniform size distribution.

Here, different sizes of SSZ-13 with a uniform size distribution were investigated. Recently, relying on the successful experience in the synthesis of different sizes of $\mathrm{Cu} / \mathrm{SAPO}-34$ with a uniform size distribution $[7,14]$, we for the first time obtained different sizes of cubic-like SSZ-13 particles with a uniform size distribution $(\mathrm{Si} / \mathrm{Al}=25)$ [6]. In the present work, we will provide more data and experimental details, using X-ray fluorescence (XRF), X-ray diffraction (XRD), and scanning electron microscopy (SEM), to corroborate further that this method can be used to synthesize the different sizes of SSZ-13 with a uniform size distribution with different Si/Al ratios (8, 15, and 25). Notably, in this work, Na/SSZ-13s were firstly synthesized and H/SSZ-13s prepared via ammonia exchange and calcination to probe the above viewpoints.

\section{Experimentation}

\subsection{Catalyst Preparation}

$\mathrm{Na} / \mathrm{SSZ}-13$ synthesis: The material sources for $\mathrm{Si}$ and $\mathrm{Al}$ were silica sol $\left(25 \mathrm{wt} \% \mathrm{SiO}_{2}\right.$, Qingdao Jiyida Silica Reagent Factory, Qingdao, China) and pseudoboehmite (68 wt $\% \mathrm{Al}_{2} \mathrm{O}_{3}$, Shandong Aluminium Industry Co., Ltd., Zibo, China), respectively. TMAda-OH (25 wt\%, Sinopec Qilu Petrochemical Co., Ltd., Zibo, China) was used as the templating agent. The gel was firstly mixed with SDA, $\mathrm{NaOH}$ liquid, and pseudoboehmite while stirring for $1 \mathrm{~h}$. Then, silica sol was added into the mixture while stirring for another $1 \mathrm{~h}$. Na/SSZ-13 was prepared using the following composition: $1 \mathrm{SiO}_{2}$ : a $(0.06 / 0.03 / 0.02)$ $\mathrm{Al}_{2} \mathrm{O}_{3}: \mathrm{b}(0.025 / 0.05 / 0.1 / 0.15) \mathrm{Na}_{2} \mathrm{O}: \mathrm{c}(0.05 / 0.1 / 0.15 / 0.2)$ SDA: $\mathrm{d}(20 / 30) \mathrm{H}_{2} \mathrm{O}$. The resulting gel was then sealed into a $200 \mathrm{~mL}$ Teflon-lined stainless steel autoclave and placed in an oven at $160^{\circ} \mathrm{C}$ for four days. After the crystallization process, the solid was separated from the mother liquid via centrifugation and 
washed with deionized water. Finally, the powder was dried in an oven at $100{ }^{\circ} \mathrm{C}$ for $12 \mathrm{~h}$ and calcined in a muffle furnace with air at $650{ }^{\circ} \mathrm{C}$ for $8 \mathrm{~h}$ to remove the template agent. Before characterization, H/SSZ-13 was prepared via ammonia exchange and calcination. The nomenclatures of the samples in Sections 2.1 and 2.2 are S-x, H-y, respectively, where $x$ stands for the number of experiments (1 to 17) and $y$ stands for the grain size of SSZ-13 under a fixed Si/Al ratio according to the SEM results.

$\mathrm{Cu} / \mathrm{SSZ}-13$ s were selected to synthesize to confirm the exchange capacity, and the synthesis process is listed in the following: $\mathrm{H} / \mathrm{SSZ}-13$ was further exchanged in a $1 \mathrm{M}\left(\mathrm{NH}_{4}\right)_{2} \mathrm{SO}_{4}$ solution at $80{ }^{\circ} \mathrm{C}$ for $4 \mathrm{~h}$ and $0.5 \mathrm{M} \mathrm{Cu}\left(\mathrm{NO}_{3}\right)_{2}$ at $80^{\circ} \mathrm{C}$ for $1 \mathrm{~h}$, respectively. The $\mathrm{Cu} / \mathrm{SSZ}-13$ s were finally obtained by calcining at $550{ }^{\circ} \mathrm{C}$ for $6 \mathrm{~h}$ in a muffle furnace.

\subsection{Catalyst Characterization}

The Si and Al concentrations of the as-prepared SSZ-13 materials were measured by X-ray fluorescence (XRF) spectroscopy. The cooper content of the obtained Cu/SSZ-13 catalysts was analyzed by inductively coupled plasma and atomic emission spectrometry (ICPAES).

Two models of Scanning electron microscopy (Hitachi Limited/FEI, Tokyo/Portland, Japan/USA) images were taken using a field emission microscope. Prior to scanning, a sample was pasted on carbon tape and then covered with an Au film for better electrical conductivity.

The XRD spectra were collected using an $X^{\prime}$ Pert Pro diffractometer (Bruker Daltonics, Karlsruhe, Baden-Württemberg, Germany) with nickel-filtered $\mathrm{Cu} K \alpha$ radiation $(\lambda=1.5418 \mathrm{~A})$ and operated at $40 \mathrm{kV}$ and $40 \mathrm{~mA}$ in the range of $5-50^{\circ}$ with a $0.01^{\circ}$ step-size. The relative crystallinity was independently normalized at each $\mathrm{Si} / \mathrm{Al}$ ratio using the total areas of five peaks $(201,003,211,104$, and 220 phase) compared with the highest crystallinity sample.

${ }^{27}$ Al NMR measurements were conducted on a Varian Infinity plus 300WB Spectrometer (VARIAN, Palo Alto, State of California, U.S), and a $\mathrm{Al}\left(\mathrm{NO}_{3}\right)_{3}$ aqueous solution was used as a reference for ${ }^{27} \mathrm{Al}$ NMR spectroscopy. Notably, the samples were pretreated at $300{ }^{\circ} \mathrm{C}$ under a vacuum for $12 \mathrm{~h}$ to remove water prior to measurements.

\section{Results and Discussion}

In this work, two methods, formula optimization and controllable preparation, are involved to illustrate how the variable sizes of SSZ-13s with a uniform size distribution in wide range of $\mathrm{Si} / \mathrm{Al}$ ratios are obtained.

\subsection{Formula Optimization for the Synthesis of Different Si/Al/SSZ-13s}

It is well known that $\mathrm{Na} / \mathrm{SSZ}-13$ materials with a wide range of $\mathrm{Si} / \mathrm{Al}$ ratios are usually obtained via hydrothermal methods using $\mathrm{Al}(\mathrm{OH})_{3}$ and colloidal silica with TMAda-OH (N,N,N-trimethyl-1-adamantammonium hydroxide) as the structure-directing agent (SDA) present in the $\mathrm{NaOH}$ solution [1]. Due to the importance of SDAs and $\mathrm{NaOH}$ for SSZ-13 materials [6,15], the SDAs related to the $\mathrm{NaOH}$ content in the precursor were considered in this study.

The optimal synthesis condition can be obtained using the designed experimental matrix that contained variable parameters of the compositions of SDAs and $\mathrm{NaOH}$. Three Si/Al ratios $(8,15,25)$ were selected as the representative and general experimental variables, as seen in Table 1 . From the viewpoint of the framework for the generation of aluminosilicates, some $\mathrm{Al}^{3+}$ substitute a fraction of the lattice $\mathrm{Si}^{4+}$, depending on the content of the SDAs. Besides that, the $\mathrm{NaOH}$ solution provides the extra lattice cations and extra $-\mathrm{OH}$, which compensate the anionic charges of the SSZ-13 materials obtained to synthesize the gel. Thus, the crystallization of SSZ-13 should generate a particular range of molar ratios in the synthesized gel. 
Table 1. The designed experimental variables ${ }^{1}$.

\begin{tabular}{cc}
\hline Variables & Values \\
\hline $\mathrm{TMAda}-\mathrm{OH} / \mathrm{Si}^{2}$ & $0.05,0.1,0.15,0.2$ \\
$\mathrm{Na}_{2} \mathrm{O} / \mathrm{Si}$ & $0.025,0.05,0.1,0.15$
\end{tabular}

${ }^{1} \mathrm{Si} / \mathrm{Al}=8,15,25 ; \mathrm{T}=160^{\circ} \mathrm{C}, \mathrm{t}=96 \mathrm{~h}, \mathrm{H}_{2} \mathrm{O} / \mathrm{Si}=20 ;$ TMAda- $\mathrm{OH}=N, N, N$-trimethyl-1-adamantammonium hydroxide; $\mathrm{Na}_{2} \mathrm{O}=2 \mathrm{NaOH} ;{ }^{2} 0.1,0.15$, and 0.2 for $\mathrm{Si} / \mathrm{Al}=8$ and $15 \mathrm{SSZ}-13 \mathrm{~s}^{\prime}$ synthesis; $0.05,0.1$, and 0.15 for SSZ-13s' synthesis with $\mathrm{Si} / \mathrm{Al}=25$.

The crystallization of SSZ-13 with $\mathrm{Si} / \mathrm{Al}=8$ under different molar ratios of $\mathrm{NaOH}$ and SDAs was firstly probed, and the results are shown in Figure 1. Less SDA and $\mathrm{NaOH}$ in the gel were unfavorable for the crystallization of SSZ-13 materials; moreover, the SSZ-13/new phase was generated when the content of $\mathrm{NaOH}$ in the gel was too high. Conversely, when SDA/Si was from 0.15 to 0.2 and $\mathrm{Na}_{2} \mathrm{O} / \mathrm{Si}$ was from 0.05 to 0.15 , only the SSZ-13 materials with $\mathrm{Si} / \mathrm{Al}=8$ could be obtained (black squares). Actually, the $\mathrm{pH}$ of all the successfully synthesized gels was measured before the gel was sealed into the Teflon-lined stainless autoclave, and the suitable $\mathrm{pH}$ levels were from 13.0 to 13.8. Accordingly, sufficient SDAs and suitable $\mathrm{pH}$ values were essential factors to determine the synthesis of SSZ-13, which strongly supported the above conclusion about the synthesis of aluminosilicates zeolites. With the increase of the Si/Al ratio of the synthesized SSZ-13, the required molar ratios of SDAs/Si and $\mathrm{Na}_{2} \mathrm{O} / \mathrm{Si}$ decreased because the content of $\mathrm{Al}$ ions in the gel decreased, as shown in Figures 2 and 3 . Again, the crystallization of SSZ-13 required suitable conditions. However, it must also be mentioned that the molar ratio of SDAs/Si was equal to 0.05 , which was too low to synthesize SSZ-13 with Si/Al = 25 in our work.

\begin{tabular}{|c|c|c|c|c|}
\hline \multirow{2}{*}{$\mathrm{Si} / \mathrm{Al}=8$} & \multicolumn{4}{|c|}{$\mathrm{Na}_{2} \mathrm{O} / \mathrm{Si}$} \\
\cline { 2 - 5 } & 0.025 & 0.05 & 0.10 & 0.15 \\
\hline SDAs $/ \mathrm{S}=0.10$ & & & & \\
\hline SDAs $/ \mathrm{S}=0.15$ & & & $\mathrm{~S}-1$ & $\mathrm{~S}-2$ \\
\hline SDAs $/ \mathrm{Si}=0.20$ & & \multicolumn{2}{|c|}{$\mathrm{S}-3$ S-4 } & \\
\hline
\end{tabular}

\begin{tabular}{|c|c|}
\hline & Amorphous \\
\hline & SSZ-13/New phase \\
\hline & SSZ-13 \\
\hline
\end{tabular}

Figure 1. The crystallization of SSZ-13 with $\mathrm{Si} / \mathrm{Al}=8$ as a function of the experimental variables in alkaline media. SDAs, structure-directing agents.

\begin{tabular}{|c|c|c|c|c|}
\hline \multirow{2}{*}{$\mathrm{Si} / \mathrm{Al}=15$} & \multicolumn{4}{|c|}{$\mathrm{Na}_{2} \mathrm{O} / \mathrm{Si}$} \\
\cline { 2 - 5 } & 0.025 & 0.05 & 0.10 & 0.15 \\
\hline $\mathrm{SDAs} / \mathrm{Si}=0.10$ & & $\mathrm{~S}-5$ & $\mathrm{~S}-6$ & \\
& $\mathrm{~S}-7$ & $\mathrm{~S}-8$ & $\mathrm{~S}-9$ & \\
\hline $\mathrm{SDAs} / \mathrm{Si}=0.15$ & $\mathrm{~S}-10$ & $\mathrm{~S}-11$ & & \\
\hline $\mathrm{SDAs} / \mathrm{Si}=0.20$ & & & & \\
\hline & & & & \\
\hline
\end{tabular}

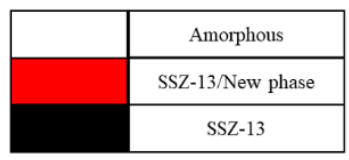

Figure 2. The crystallization of SSZ-13 with $\mathrm{Si} / \mathrm{Al}=15$ as a function of the experimental variables in alkaline media. 


\begin{tabular}{|c|c|c|c|c|}
\hline \multirow{2}{*}{$\mathrm{Si} / \mathrm{Al}=25$} & \multicolumn{4}{|c|}{$\mathrm{Na}_{2} \mathrm{O} / \mathrm{Si}$} \\
\hline & 0.025 & 0.05 & 0.10 & 0.15 \\
\hline $\mathrm{SDAs} / \mathrm{Si}=0.05$ & & & & \\
\hline $\mathrm{SDAs} / \mathrm{Si}=0.10$ & $\mathrm{~S}-12$ & $\mathrm{~S}-13$ & $\mathrm{~S}-14$ & \\
\hline $\mathrm{SDAs} / \mathrm{Si}=0.15$ & $\mathrm{~S}-15$ & $\mathrm{~S}-16$ & & \\
\hline & & & & \\
\hline
\end{tabular}

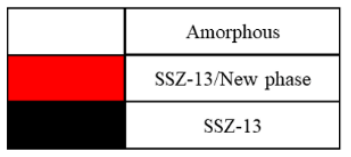

Figure 3. The crystallization of SSZ-13 with $\mathrm{Si} / \mathrm{Al}=25$ as a function of the experimental variables in alkaline media.

The crystalline SSZ-13 materials of different $\mathrm{Si} / \mathrm{Al}$ ratios were measured by $\mathrm{XRD}$, and the results are shown in Figure 4. As shown in Figure 4a to c, the as-prepared SSZ-13 materials showed the typical CHA phase $[16,17]$. To clarify the effect of the synthesis conditions on the crystallinity of SSZ-13, the relative crystallinities for each $\mathrm{Si} / \mathrm{Al}$ ratio were independently normalized and are displayed in Figure $4 \mathrm{~d}$ to $\mathrm{f}$. The results showed that the crystallinity of the as-prepared SSZ- 13 decreased as the $\mathrm{pH}$ values at fixed molar ratios of SDAs/Si or $\mathrm{Na}_{2} \mathrm{O} / \mathrm{Si}$ as the TMAda-OH $(25 \mathrm{wt} \%)$ and $\mathrm{NaOH}(48 \mathrm{wt} \%)$ solution used in our work showed strong alkalinity. Clearly, to determine the best synthesis condition, the results of the chemical composition of crystalline SSZ-13 should be considered, and the results are shown in Table 2 . For the synthesis of SSZ-13 with $\mathrm{Si} / \mathrm{Al}=8$, the $\mathrm{Si} / \mathrm{Al}$ ratios of S- 1 and S-2 showed a great difference from those of the prepared gel (eight), which illustrated that the molar ratio of SDAs/Si $=0.15$ was not enough to ensure that all the $\mathrm{Al}$ ions entered the CHA framework. Taking the relative crystallinity into account, the synthesis condition of $\mathrm{SSZ}-13$ with $\mathrm{Si} / \mathrm{Al}=8$ was the best choice for Sample 3 (S-3). Furthermore, for the synthesis of SSZ-13 with larger Si/Al ratios (15 and 25), it was easy to claim that the synthesis conditions of S- 5 and S- 12 were the optimal ones when considering similar relative crystallinities (S-5 and S-7 for Si/Al $=15 ; \mathrm{S}-12$ and S-15 for Si/Al $=25$ ) and real Si/Al ratios at the same time.
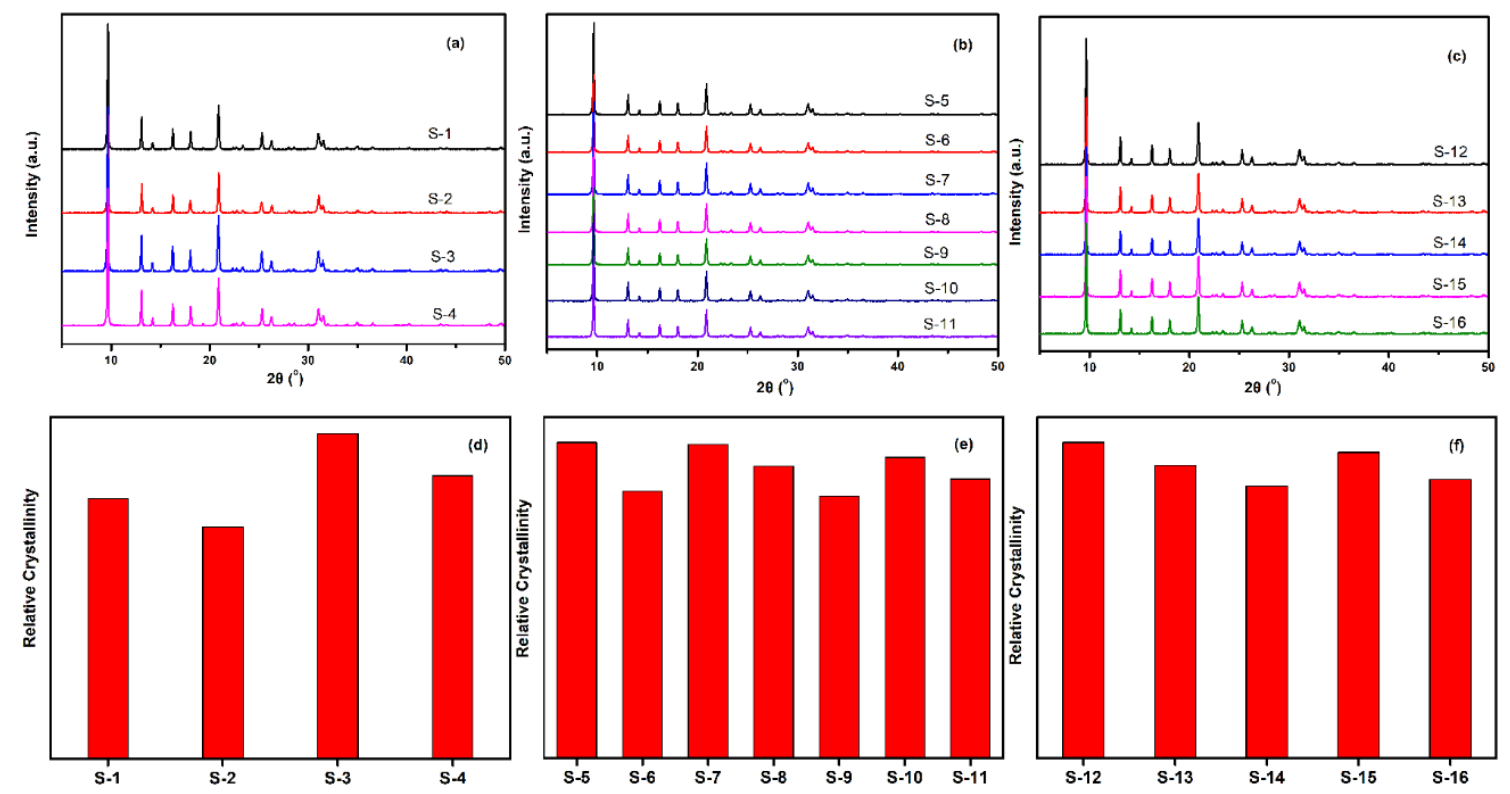

Figure 4. XRD pattern (top) and relative crystallinity (bottom) of SSZ-13 with different Si/Al ratios. $(\mathbf{a}, \mathbf{d})$ for Si/Al = 8 SSZ-13 materials; $(\mathbf{b}, \mathbf{e})$ for Si/Al = 15 SSZ-13 materials; $(\mathbf{c}, \mathbf{f})$ for Si/Al = 25 SSZ-13 materials. S-1, Sample 1. 
Table 2. Si/Al ratios for the obtained SSZ-13s.

\begin{tabular}{cccc}
\hline Sample & Si/Al & Sample & Si/Al \\
\hline S-1 & 11.8 & S-9 & 15.1 \\
S-2 & 11.3 & S-10 & 14.6 \\
S-3 & 8.2 & S-11 & 15.2 \\
S-4 & 8.9 & S-12 & 24.7 \\
S-5 & 15.3 & S-13 & 25.6 \\
S-6 & 15.2 & S-14 & 23.8 \\
S-7 & 15.6 & S-15 & 24.5 \\
S-8 & 14.9 & S-16 & 25.2 \\
\hline
\end{tabular}

At this point, we obtained the optimal condition for the synthesis of SSZ-13 in wide range of Si/Al ratios. Within this optimal condition, the processes of how the different sizes of SSZ-13 with a uniform size distribution were obtained will be illustrated in the following part.

\subsection{Synthesis of Different Sizes of SSZ-13 Materials}

According to the former studies $[7,18,19]$, the change of the grain size is related to the relative rate of nucleation and crystallization growth, and the supersaturation of the precursor is a critical factor influencing the growth rate. Hence, the supersaturation in the synthesized gel with a simple method should be considered a priority, like directly changing the $\mathrm{pH}$ or the water content or the addition of the seed in the synthesized gel. Therefore, each variable was changed independently to better investigate how these variables influenced the grain size of SSZ-13.

First, let us quickly review the experiments to regulate the $\mathrm{pH}$ values via adding different $\mathrm{Na}_{2} \mathrm{O} / \mathrm{Si}$ rations in the gel when synthesizing $\mathrm{Si} / \mathrm{Al}=25 \mathrm{SSZ}-13$ as an example. To gain more insight into the morphological changes while altering the $\mathrm{pH}$ values, the resultant SSZ-13s of S-12 and S-14 were characterized using SEM, and the results are shown in Figure 5. The higher pH values resulted in high supersaturation of the precursor, which would cause smaller grain sizes; whereas, two samples showed cubic crystals with a similar average size $(\sim 2 \mu \mathrm{m})$, which illustrated that the grain size was not sensitive to the $\mathrm{pH}$ value. This is easy to understand because the range of suitable $\mathrm{pH}$ values for SSZ-13 synthesis is narrow (13.0 13.8). Thus, it is reasonable believe that altering the $\mathrm{pH}$ value was not a feasible approach to obtain SSZ-13s with different sizes.

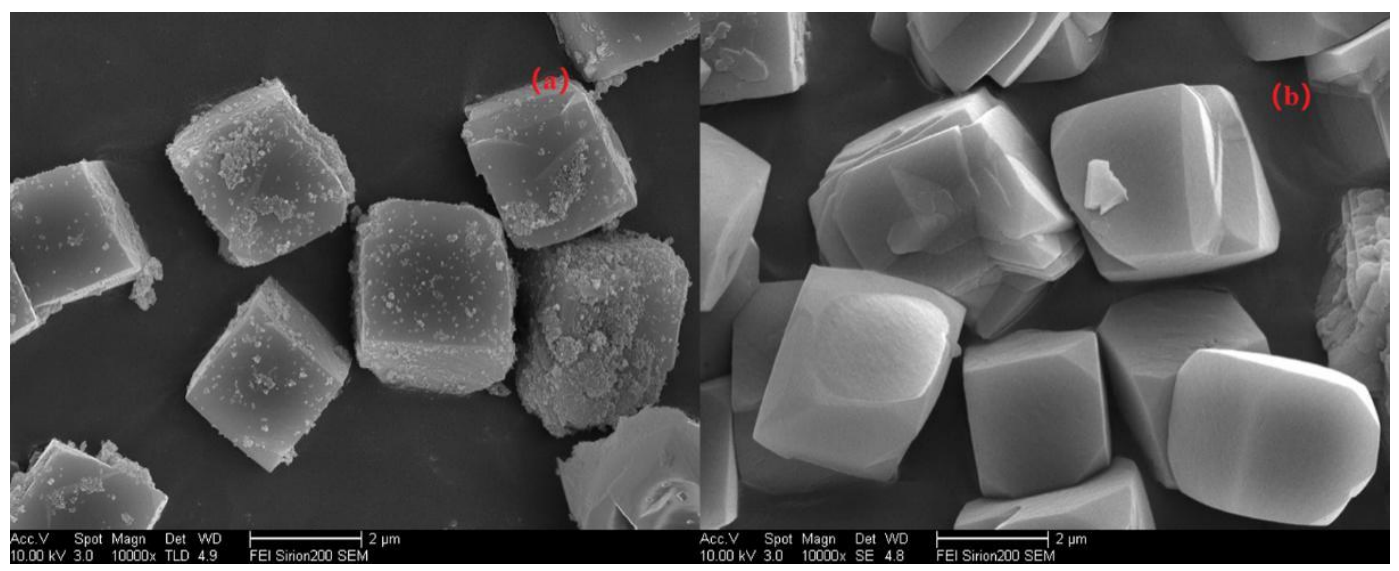

Figure 5. SEM images of S-12 (a) and S-14 (b).

Next, another question is whether the molar ratio of $\mathrm{H}_{2} \mathrm{O} / \mathrm{Si}$ could alter the grain size of the as-prepared SSZ-13, and this will be answered by running a series of comparative experiments that only change the $\mathrm{H}_{2} \mathrm{O} / \mathrm{Si}$ molar ratios. In this case, SSZ-13 with $\mathrm{Si} / \mathrm{Al}=25$ was still chosen. Additionally, to avoid large fluctuations of the $\mathrm{pH}$ values caused by more water addition, resulting in 
no crystallization [20], we preferred to use more $\mathrm{NaOH}$, and the detailed experiments are shown in Figure 6. Again, changing the water content could adjust the supersaturation of the precursor, and this would in turn make the grain size of the as-prepared SSZ-13 change. However, the result of SEM in Figure 7 shows that the increase in $\mathrm{H}_{2} \mathrm{O} / \mathrm{Si}$ ratios could make the SZZ-13 material crystallize, and the morphology of these two samples did not show much difference, especially the grain size. Notably, if these samples were further examined by XRF (Table 3), the Si/Al ratio of S-17 was 50.6, which was twice as big as the feed ratio (15). Considering all these facts, changing the water content is not also a universal method to adjust the grain size of SSZ-13. At this point, adjusting the pH value and water content was not a practical solution to alter the grain size.
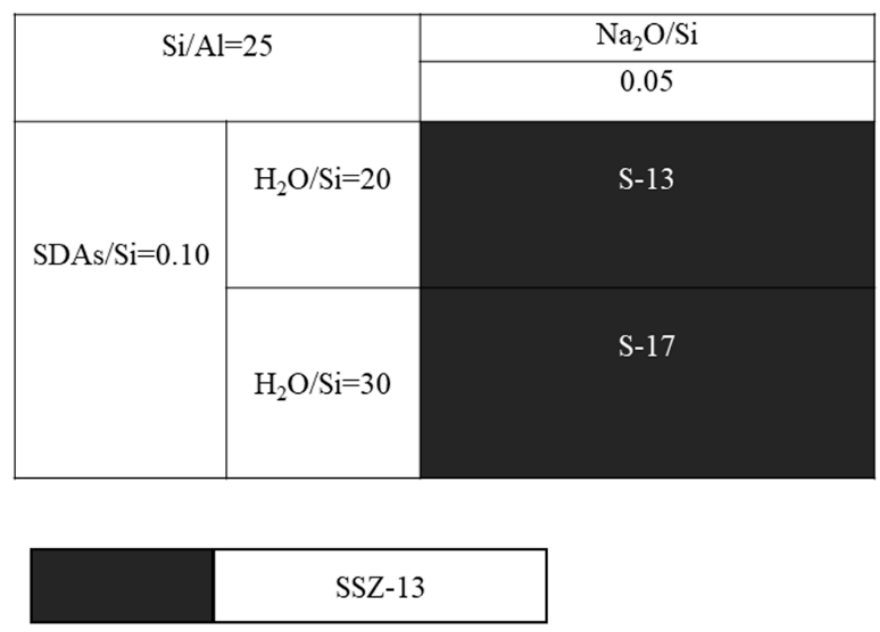

Figure 6. SEM images of S-13 and S-17.

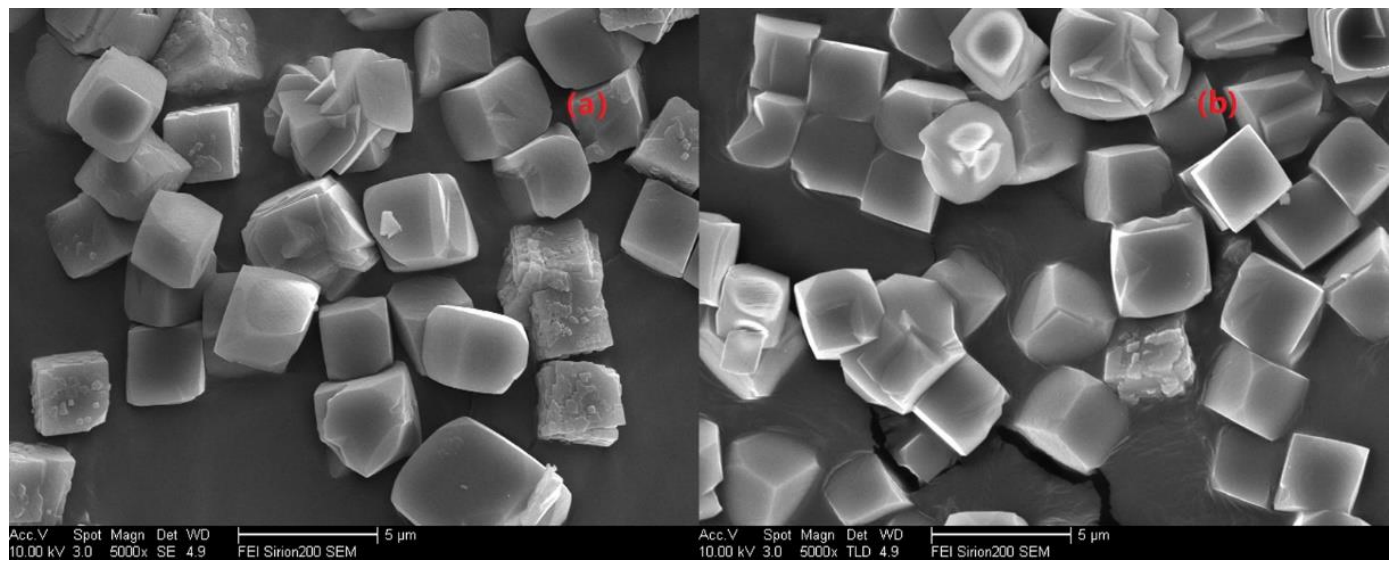

Figure 7. The crystallization of SSZ-13 with $\mathrm{Si} / \mathrm{Al}=25$ as a function of the $\mathrm{H}_{2} \mathrm{O} / \mathrm{Si}$ ratios in alkaline media. (a) S-13; (b) S-17.

Table 3. Si/Al ratios for the obtained SSZ-13s.

\begin{tabular}{cc}
\hline Sample & Si/Al \\
\hline S-13 & 25.6 \\
S-17 & 50.6 \\
\hline
\end{tabular}

In the end, the method of adding the seed into the precursor gel was applied to illustrate how this approach gradually achieved the final goal of this work. It is well known that seed addition, usually used for the as-prepared zeolite, can act as a crystal nucleation site to synthesize zeolites [21,22]. In the same way, the as-prepared SSZ-13 could be used as the seed, and a greater amount of seed addition 
should result in the equal increase of the crystal nucleation sites in the gel. As the reactant is limited in the synthesized gel, introducing more crystal nucleation sites amounts to helping to generate a smaller crystal size [7].

Drawing on this idea, the grain size of the as-prepared SSZ-13 materials was determined by using the above optimized Si/Al = 25 SSZ-13s (S-12) as the seeds. Now, two points need special attention. One is that seeds having the same $\mathrm{Si} / \mathrm{Al}$ ratio as the final sample should be used because this would effectively prevent the samples having different $\mathrm{Si} / \mathrm{Al}$ ratios at the inner and outer layers [12]. The other is that SSZ-13 should be ground before being added into the precursor gel. In fact, different amounts of SSZ-13 without milling as seeds were used to change the size of SSZ-13 materials with Si/Al = 25 in our pre-experiments. However, the grain size of the as-prepared SSZ-13 with Si/Al = 25 could only be reduced from 2 to $1.5 \mu \mathrm{m}$ when the amount of seeds added reached $40 \mathrm{wt} \%$, which showed that a moderating effect of size was not obvious if SSZ-13 without milling was used. A reasonable explanation is that SSZ-13s without milling were too large compared with the crystal nucleus, and hence, these were not suitable sites to allow the reactants to continue to crystallize. If the optimized SSZ-13s (S-12) were ground in a ball mill for $0.5 \mathrm{~h}$ before synthesis, the size of the as-prepared SSZ-13s could be effectively controlled from 2 to $0.4 \mu \mathrm{m}$ (Figure 8) when the additive amounts increased from $0 \%$ to $1 \%$ (Table 4 ). It is also important to highlight that the size distribution of every obtained sample with cubic-like particles was uniform. Moreover, compared to SSZ-13 synthesis with unground seed, the amount of ground seed addition could be effectively decreased (from $40 \%$ to $1 \%$ ). The obtained results suggested that a suitable approach for the adjustment of the size was using the ground SSZ-13 materials as seeds before crystallization.

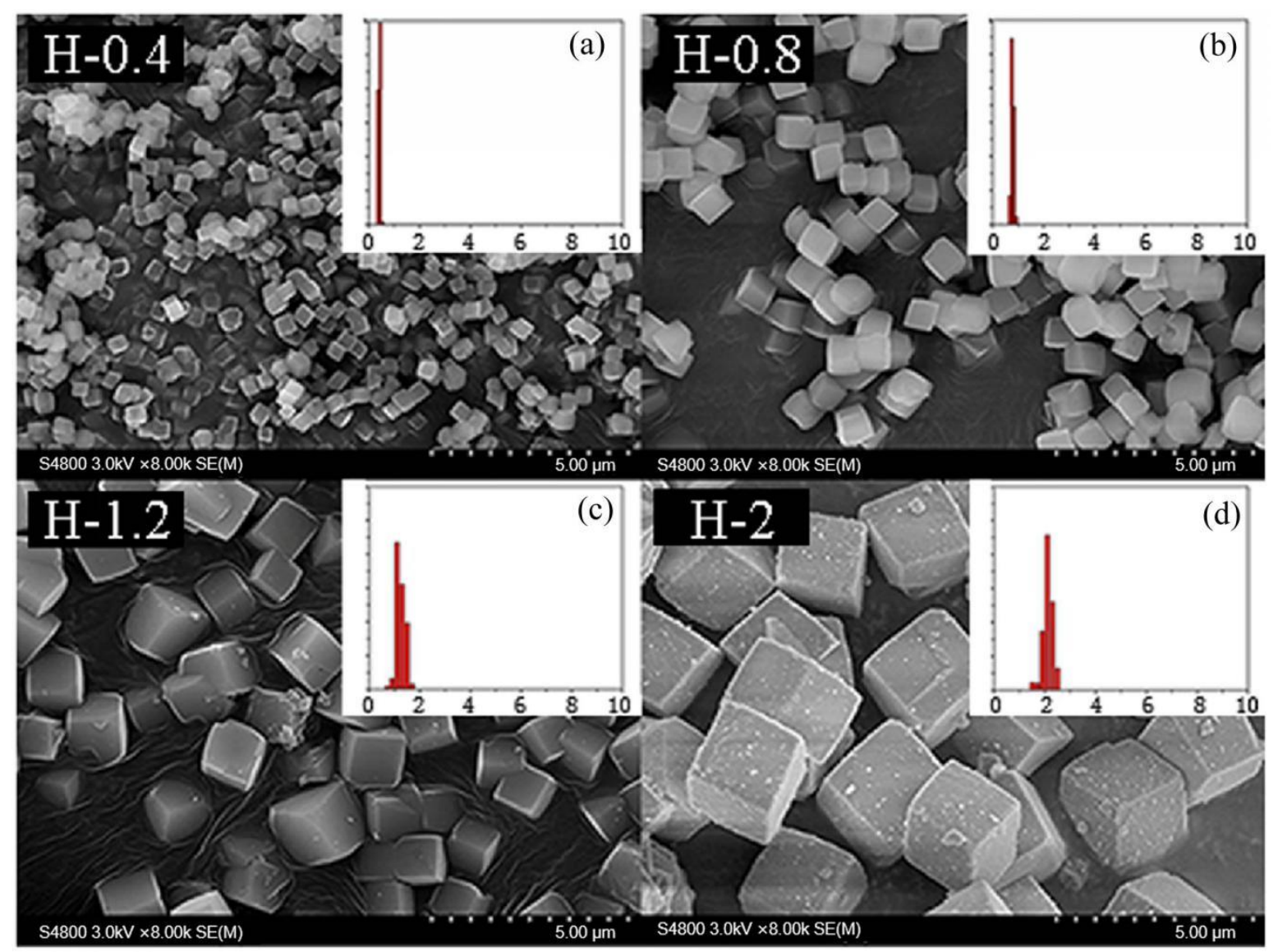

Figure 8. The SEM results of SSZ-13 with different sizes ( $\mathrm{Si} / \mathrm{Al}=25)$. (a) $\mathrm{H}-0.4$; (b) $\mathrm{H}-0.8$; (c) $\mathrm{H}-1.2$; (d) H-2. Synthesized gel compositions: $1 \mathrm{SiO}_{2}: 0.02 \mathrm{Al}_{2} \mathrm{O}_{3}: 0.025 \mathrm{Na}_{2} \mathrm{O}: 0.1$ SDA: $20 \mathrm{H}_{2} \mathrm{O}$. 
Table 4. Relationship between seed addition and the obtained particle size.

\begin{tabular}{cc}
\hline The Size of As-Prepared SSZ-13 $(\boldsymbol{\mu m})$ & The Amount of Seed Addition $(\%)$ \\
\hline 2 & 0 \\
1.2 & 0.01 \\
0.8 & 0.1 \\
0.4 & 1 \\
\hline
\end{tabular}

Could extending the grinding time improve the morphology of the samples? This question could be answered by running a series of comparative experiments using $1 \%$ ground seed with $1 \mathrm{~h}$ of grinding under identical synthesis conditions as that of the sample ground for $0.5 \mathrm{~h}$. The SEM results in Figure 9 show that a longer grinding time led to inhomogeneous crystals of SSZ-13 materials, manifesting that a longer grinding time was not helpful to obtain a good morphology of the as-prepared SSZ-13. As shown in Figure 10, after $0.5 \mathrm{~h}$ of grinding, the uniformity of the size distribution of the as-prepared SSZ-13 materials should be relative to the degree of uniformity of the ground seeds. Here, the optimum condition for obtaining the variable grain sizes of SSZ-13 $(\mathrm{Si} / \mathrm{Al}=25)$ with a uniform size distribution was finally achieved.

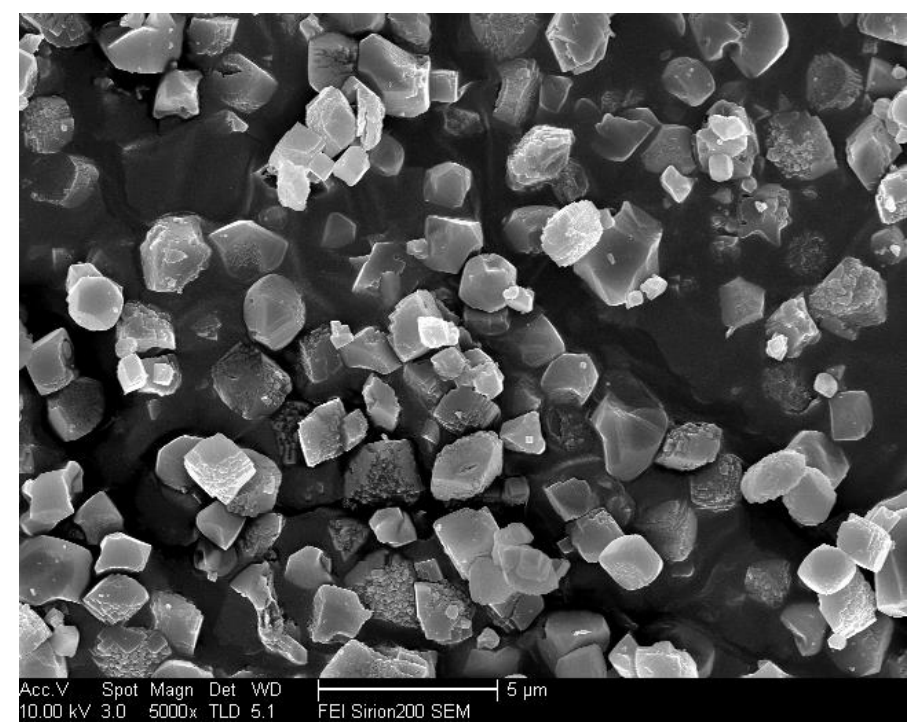

Figure 9. The SEM result of the as-prepared SSZ-13 using ground seeds with $1 \mathrm{~h}$ grinding.

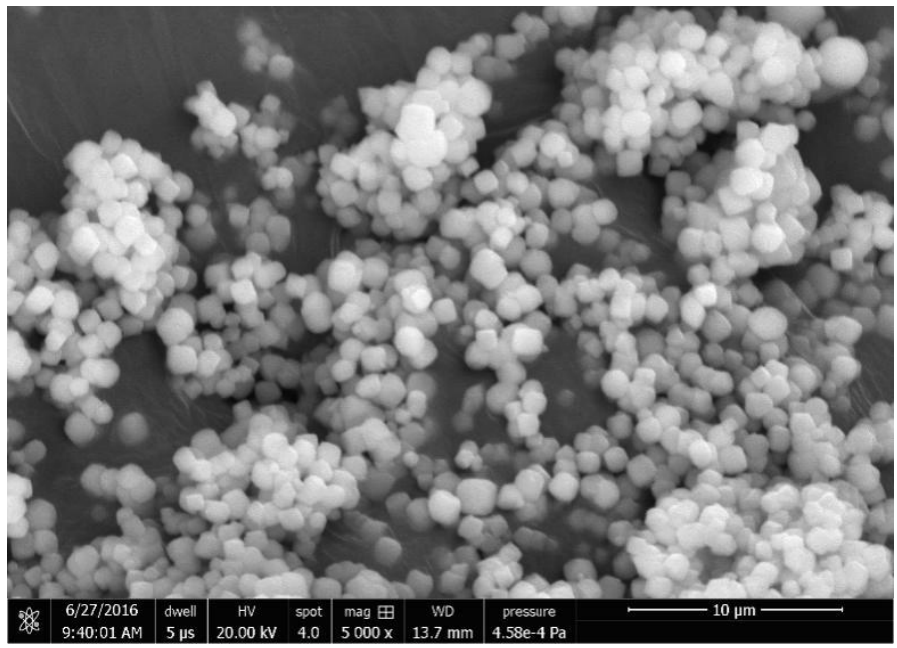

Figure 10. The SEM results of $0.5 \mathrm{~h}$ of seed grinding. 
To further confirm that the above optimal condition was a universal method, SSZ-13s with different $\mathrm{Si} / \mathrm{Al}$ ratios were also synthesized using ground seed under the optimized synthesis formula in Section 2.1. As shown in Figures 11 and 12, the different sizes and uniform size distribution of the as-prepared SSZ-13s with Si/Al ratios equal to eight and 15 could also be obtained, verifying that using ground seed was a practical solution to deal with the grain size of SSZ-13 materials.

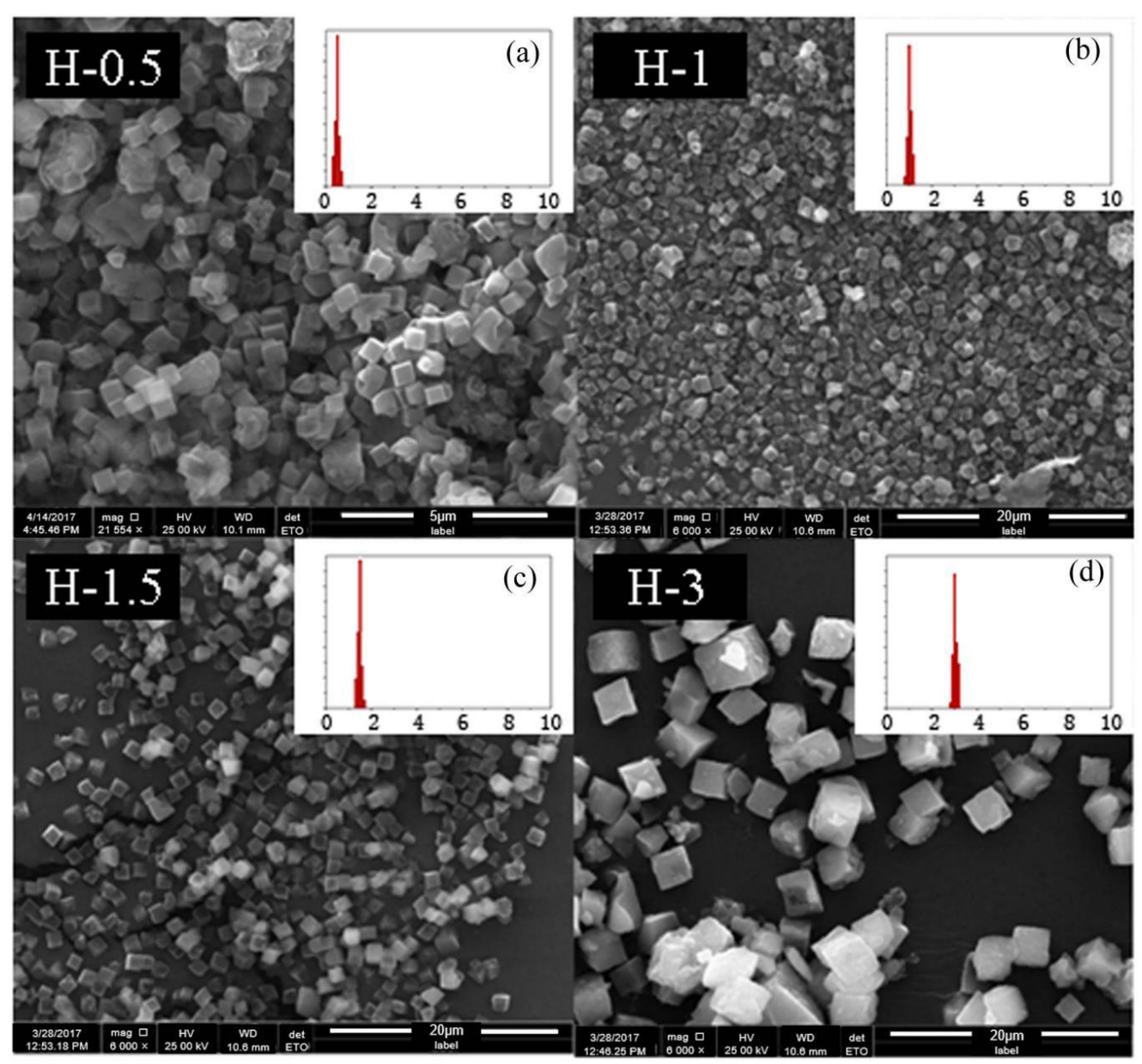

Figure 11. The SEM results of SSZ-13 with different sizes ( $\mathrm{Si} / \mathrm{Al}=8)$. (a) $\mathrm{H}-0.5$; (b) $\mathrm{H}-1$; (c) $\mathrm{H}-1.5$; (d) H-3. Synthesized gel compositions: $1 \mathrm{SiO}_{2}$ : $0.06 \mathrm{Al}_{2} \mathrm{O}_{3}: 0.05 \mathrm{Na}_{2} \mathrm{O}: 0.2 \mathrm{SDA}: 20 \mathrm{H}_{2} \mathrm{O}$.

To gain a better understanding of the crystallinity and chemical compositions of the above samples with different sizes, the samples were further measured by XRD and XRF. From the results of Figure 13 and Table 5, all synthesized samples had a similar relative crystallinity and chemical composition under each Si/Al ratio. The next question for the obtained material was whether the as-prepared SSZ-13s with different grain sizes under the special Si/Al ratio also had a similar acidity. To confirm the above suggestion, ${ }^{27} \mathrm{Al}$ NMR measurements of all samples were performed because the acidity of SSZ-13s resulted from $\mathrm{Al}$ atom insertion into the CHA structure [1]. As shown in Figure 14, the samples with different grain sizes had basically the same intensity for the $\mathrm{Al}$ peaks (lattice $\mathrm{Al}$ and extra-lattice $\mathrm{Al}$ ), which manifested that the micro-chemical environments of Al were identical. Considering that the identical chemical environment of Al resulted in the same acidity [6], the above results indicated that the different sizes of SSZ-13s with a similar Si/Al ratio had similar acidity. Moreover, the above results also indicated that adding different amounts of seeds alone adjusted the size of the as-prepared SSZ-13 materials, rather than other features. Again, adding the different amounts of ground seeds was a helpful approach to gain different sizes of SSZ-13 crystals. 


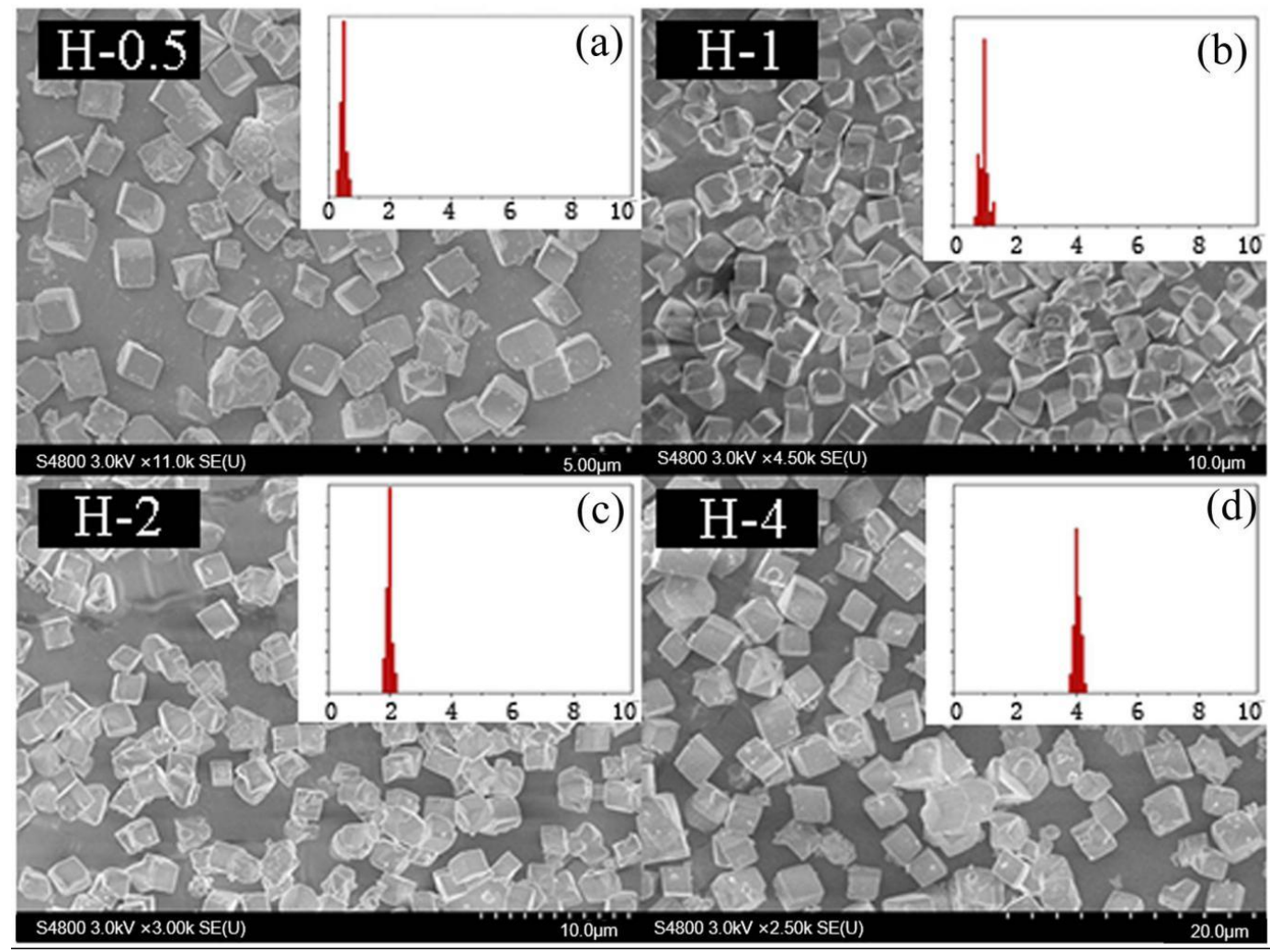

Figure 12. The SEM results of SSZ-13 with different sizes ( $\mathrm{Si} / \mathrm{Al}=15)$. (a) $\mathrm{H}-5$; (b) $\mathrm{H}-1$; (c) $\mathrm{H}-2$; (d) $\mathrm{H}-4$. Synthesized gel compositions: $1 \mathrm{SiO}_{2}$ : $0.03 \mathrm{Al}_{2} \mathrm{O}_{3}$ : $0.05 \mathrm{Na}_{2} \mathrm{O}$ : 0.1 SDA: $20 \mathrm{H}_{2} \mathrm{O}$.
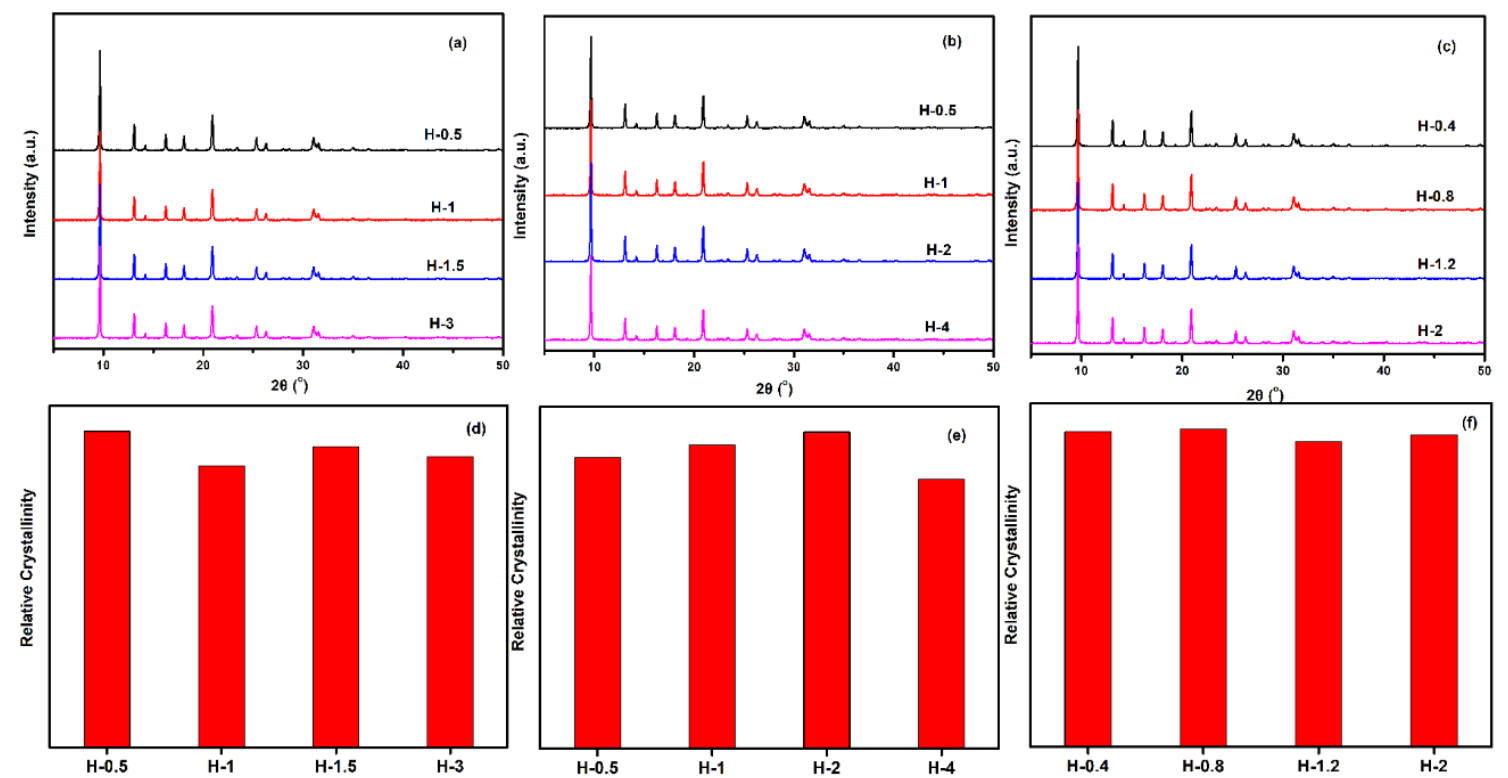

Figure 13. XRD pattern (top) and relative crystallinity (bottom) of SSZ-13s with different sizes. (a,d) for $\mathrm{Si} / \mathrm{Al}=8 \mathrm{SSZ}-13$ materials; $(\mathbf{b}, \mathbf{e})$ for Si/Al = 15 SSZ-13 materials; $(\mathbf{c}, \mathbf{f})$ for Si/Al = 25 SSZ-13 materials. Notes: The relative crystallinities for each $\mathrm{Si} / \mathrm{Al}$ ratio were independently normalized.

Here, as adding ground seeds is an easy method to carry out in industry, this approach is very suitable for industrial production of SSZ-13 crystals. Additionally, in combination with the successful case of synthesizing different sizes of SAPO-34 with an identical method, it is reasonable to believe that adding the ground seeds may also prove a useful method to synthesize other types of zeolites. 
Table 5. Si/Al ratios for the obtained SSZ-13s with $\mathrm{Si} / \mathrm{Al}=8,15$, and 25.

\begin{tabular}{cccccc}
\hline $\begin{array}{c}\text { Samples with } \\
\text { Low Si/Al }\end{array}$ & Si/Al & $\begin{array}{c}\text { Samples with } \\
\text { Middle Si/Al }\end{array}$ & Si/Al & $\begin{array}{c}\text { Samples with } \\
\text { High Si/Al }\end{array}$ & Si/Al \\
\hline H-0.5 & 7.8 & H-0.5 & 14.5 & H-0.4 & 23.6 \\
H-1 & 8.3 & H-1 & 15.1 & H-0.8 & 24.8 \\
H-1.5 & 7.6 & H-2 & 14.2 & H-1.2 & 23.9 \\
H-3 & 8.5 & H-4 & 13.4 & H-2 & 24.5 \\
\hline
\end{tabular}
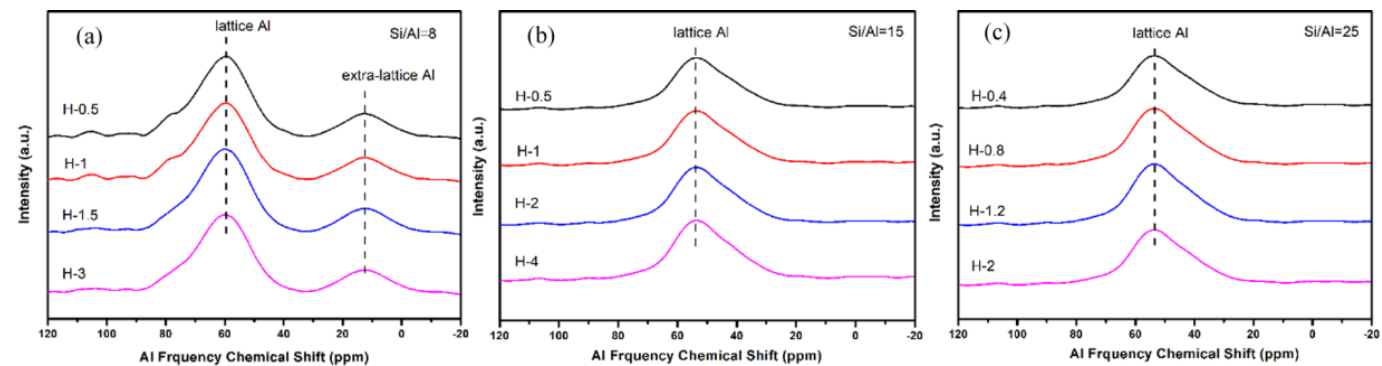

Figure 14. ${ }^{27} \mathrm{Al}$ NMR results of SSZ-13 with different sizes at different $\mathrm{Si} / \mathrm{Al}$ ratios. (a) $\mathrm{Si} / \mathrm{Al}=8$; (b) $\mathrm{Si} / \mathrm{Al}=15 ;(\mathbf{c}) \mathrm{Si} / \mathrm{Al}=25$.

\section{Conclusions}

The synthesis of SSZ-13 materials with variable grain sizes and a uniform size distribution was systematically investigated, and the detailed synthesis process was given. The main conclusions of this work are listed in the following:

1. The SDA content was an essential factor to determine the $\mathrm{Al}$ entering the $\mathrm{CHA}$ framework, and hence, the molar ratios of SDAs/Si could not be lower than 0.1 in our work.

2. The molar ratios of $\mathrm{Na}_{2} \mathrm{O} / \mathrm{Si}$ also affected the SSZ-13 crystallinity as too high or too low contents did not benefit the synthesis of SSZ-13. The $\mathrm{pH}$ value centered between 13 and 13.8 was an appropriate condition for crystallization.

3. Due to the limitation of the synthetic $\mathrm{pH}$ value, the change of supersaturation via turning alkaline and water content was not suitable to generate different grain sizes of SSZ-13s.

4. Under fixed compositions of the precursor gel, the addition of different contents (0 to $1 \%)$ of ground SSZ-13 as seeds was an effective and easy way to synthesize different grain sizes $(0.4$ to $4 \mu \mathrm{m})$ of SSZ-13 materials with a uniform size distribution with different Si/Al ratios $(8,15$, and 25$)$.

5. Our study suggested that adding seeds was very suitable for the industrial production of SSZ-13 crystals and may also be a useful method to synthesize other types of zeolites in the future.

Author Contributions: Conceptualization, C.W.; formal analysis, J.W. (Jianqiang Wang); funding acquisition, Y.W., J.W. (Jun Wang), M.S., and C.W.; investigation, C.W., Y.W., L.W., and C.X.; methodology, J.W. (Jun Wang) and M.S.; project administration, J.W. (Jun Wang); resources, M.S.; supervision, C.W. and M.S.; validation, J.W. (Jianqiang Wang), C.X. and L.W.; visualization, C.W.; writing, review and editing, C.W. and Y.W. All authors have read and agreed to the published version of the manuscript.

Funding: This research was funded by the Science Fund of the State Key Laboratory of Engine Reliability, Grant Number skler-201714; the National Key Research and Development program, Grant Number 2017YFC0211302; the National Natural Science Foundation of China, Grant Number 21676195; the National Natural Science Foundation of China for Youths, Grant Number 21908207; and the Shanxi Province Science Foundation for Youths, Grant Number 201901D211224.

Conflicts of Interest: The authors declare no conflict of interest. 


\section{References}

1. Paolucci, C.; Di Iorio, J.R.; Ribeiro, F.; Gounder, R.; Schneider, W.F. Catalysis Science of NOx Selective Catalytic Reduction with Ammonia Over Cu-SSZ-13 and Cu-SAPO-34. Adv. Catal. 2016, 59, 1-107.

2. Kong, C.; Zhu, J.; Liu, S.; Wang, Y. SAPO-34 with a low acidity outer layer by epitaxial growth and its improved MTO performance. RSC Adv. 2017, 7, 39889-39898. [CrossRef]

3. Huang, F.; Cao, J.; Wang, L.; Wang, X.; Liu, F. Enhanced catalytic behavior for methanol to lower olefins over SAPO-34 composited with $\mathrm{ZrO}_{2}$. Chem. Eng. J. 2020, 380, 122626. [CrossRef]

4. Mohan, S.; Dinesha, P.; Kumar, S. NOx reduction behaviour in copper zeolite catalysts for ammonia SCR systems: A review. Chem. Eng. J. 2020, 384, 123253. [CrossRef]

5. Xu, Z.; Li, J.; Huang, Y.; Ma, H.; Qian, W.; Zhang, H.; Ying, W. Size control of SSZ-13 crystals with APAM and its influence on the coking behaviour during MTO reaction. Catal. Sci. Technol. 2019, 9, 2888-2897. [CrossRef]

6. Wang, J.; Shao, L.; Wang, C.; Wang, J.; Shen, M.; Li, W. Controllable preparation of various crystal size and nature of intra-crystalline diffusion in Cu/SSZ-13 NH3-SCR catalysts. J. Catal. 2018, 367, 221-228. [CrossRef]

7. Huang, S.; Wang, J.; Wang, J.; Wang, C.; Shen, M.; Li, W. The influence of crystallite size on the structural stability of Cu/SAPO-34 catalysts. Appl. Catal. B Environ. 2019, 248, 430-440. [CrossRef]

8. Martín, N.; Li, Z.; Triguero, J.M.; Yu, J.; Moliner, M.; Corma, A. Nanocrystalline SSZ-39 zeolite as an efficient catalyst for the methanol-to-olefin (MTO) process. Chem. Commun. 2016, 52, 6072-6075. [CrossRef]

9. Lin, S.; Li, J.; Sharma, R.P.; Yu, J.; Xu, R. Fabrication of SAPO-34 Crystals with Different Morphologies by Microwave Heating. Top. Catal. 2010, 53, 1304-1310. [CrossRef]

10. Wang, C.; Yang, M.; Tian, P.; Xu, S.; Yang, Y.; Wang, D.; Yuan, Y.; Liu, Z. Dual template-directed synthesis of SAPO-34 nanosheet assemblies with improved stability in the methanol to olefins reaction. J. Mater. Chem. A 2015, 3, 5608-5616. [CrossRef]

11. Wang, P.; Yang, D.; Hu, J.; Xu, J.; Lu, G. Synthesis of SAPO-34 with small and tunable crystallite size by two-step hydrothermal crystallization and its catalytic performance for MTO reaction. Catal. Today 2013, 212, 62.e1-62.e8. [CrossRef]

12. Yang, M.; Tian, P.; Wang, C.; Yuan, Y.; Yang, Y.; Xu, S.; He, Y.; Liu, Z. A top-down approach to prepare silicoaluminophosphate molecular sieve nanocrystals with improved catalytic activity. Chem. Commun. 2014, 50, 1845-1847. [CrossRef] [PubMed]

13. Li, Z.; Navarro, M.T.; Triguero, J.M.; Yu, J.; Corma, A. Synthesis of nano-SSZ-13 and its application in the reaction of methanol to olefins. Catal. Sci. Technol. 2016, 6, 5856-5863. [CrossRef]

14. Hu, X.; Yang, M.; Fan, D.; Qi, G.; Wang, J.; Wang, J.; Yu, T.; Li, W.; Shen, M. The role of pore diffusion in determining NH3 SCR active sites over Cu/SAPO-34 catalysts. J. Catal. 2016, 341, 55-61. [CrossRef]

15. Shen, M.; Wang, Z.; Li, X.; Wang, J.; Wang, J.; Wang, C.; Wang, J. Effects of regeneration conditions on sulfated CuSSZ-13 catalyst for NH3-SCR. Korean J. Chem. Eng. 2019, 36, 1249-1257. [CrossRef]

16. Zhao, H.; Zhao, Y.; Ma, Y.; Yong, X.; Wei, M.; Chen, H.; Zhang, C.; Li, Y. Enhanced hydrothermal stability of a Cu-SSZ-13 catalyst for the selective reduction of NOx by NH3 synthesized with SAPO-34 micro-crystallite as seed. J. Catal. 2019, 377, 218-223. [CrossRef]

17. Xie, K.; Woo, J.; Bernin, D.; Kumar, A.; Kamasamudram, K.; Olsson, L. Insights into hydrothermal aging of phosphorus-poisoned Cu-SSZ-13 for NH3-SCR. Appl. Catal. B Environ. 2019, 241, 205-216. [CrossRef]

18. Nishiyama, N.; Kawaguchi, M.; Hirota, Y.; Van Vu, D.; Egashira, Y.; Ueyama, K. Size control of SAPO-34 crystals and their catalyst lifetime in the methanol-to-olefin reaction. Appl. Catal. A Gen. 2009, 362, 193-199. [CrossRef]

19. Iwase, Y.; Motokura, K.; Koyama, T.-R.; Miyaji, A.; Baba, T. Influence of Si distribution in framework of SAPO-34 and its particle size on propylene selectivity and production rate for conversion of ethylene to propylene. Phys. Chem. Chem. Phys. 2009, 11, 9268. [CrossRef]

20. Martínez-Franco, R.; Moliner, M.; Thogersen, J.R.; Corma, A. Efficient One-Pot Preparation of Cu-SSZ-13 Materials using Cooperative OSDAs for their Catalytic Application in the SCR of NOx. ChemCatChem 2013, 5, 3316-3323. [CrossRef] 
21. Liu, X.; Jia, X.; Guo, X.; Zhang, Z.; Ma, H.-A. Experimental Evidence for Nucleation and Growth Mechanism of Diamond by Seed-Assisted Method at High Pressure and High Temperature. Cryst. Growth Des. 2010, 10, 2895-2900. [CrossRef]

22. Suganuma, S.; Zhang, H.; Yang, C.; Xiao, F.-S.; Katada, N. Acidic property of BEA zeolite synthesized by seed-directed method. J. Porous Mater. 2015, 23, 415-421. [CrossRef]

(C) 2020 by the authors. Licensee MDPI, Basel, Switzerland. This article is an open access article distributed under the terms and conditions of the Creative Commons Attribution (CC BY) license (http://creativecommons.org/licenses/by/4.0/). 